AIRWAY BIOLOGY

\title{
Dendritic cell subsets in human bronchoalveolar lavage fluid after segmental allergen challenge
}

\author{
Kai Bratke, Marek Lommatzsch, Peter Julius, Michael Kuepper, Hans-Dieter Kleine, Werner \\ Luttmann, J Christian Virchow
}

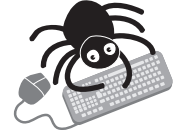

Figure $A$ and table $A$ are available at http://thorax. bmijournals.com/ supplemental

See end of article for authors' affiliations

Correspondence to DrM Lommatzsch, Abteilung für Pneumologie, Klinik und Poliklinik für Innere Medizin, Universität Rostock, Ernst-

Heydemann-Str. 6, Rostock 18057, Germany; marek.lommatzsch@ med.uni-rostock.de

Received 26 June 2006 Accepted 4 August 2006

Published Online First 23 August 2006
Thorax 2007:62:168-175 doi: 10.1136/thx.2006.067793

\begin{abstract}
Background: Dendritic cells control pulmonary immune reactions. Characteristics of dendritic cells in human bronchoalveolar lavage fluid (BALF) after allergen challenge are unknown.

Methods: 7 patients with allergic asthma (median 23 years, range 19-25 years) underwent segmental challenge and were lavaged $10 \mathrm{~min}$ and $24 \mathrm{~h}$ after challenge. Dendritic cell subsets and surface markers in BALF and in peripheral blood were analysed using four-colour flow cytometry.

Results: Plasmacytoid dendritic cells ( $\mathrm{pDCs}$, median $0.06 \%$, range $0.01-0.08 \%$ ) and myeloid dendritic cells (mDCs, median $0.47 \%$, range $0.27-0.87 \%$ ) were detectable in BALF from control segments. CDla-positive dendritic cells in BALF were identified as a subpopulation of $\mathrm{mDCs}$. Both $\mathrm{pDCs}$ (median $0.56 \%$, range 0.09 $1.83 \%$ ) and $\mathrm{mDCs}$ (median 1.82\%, range $0.95-2.29 \%$ ) increased significantly in BALF $24 \mathrm{~h}$ ( $\mathrm{p}=0.018$ compared with the control segments for $\mathrm{pDCs}$ and $\mathrm{mDCs}$ ), but not $10 \mathrm{~min}$, after allergen challenge. The percentage increase in $\mathrm{pDC}$ s was higher than that of $\mathrm{mDCs}$ after allergen challenge, as reflected by an enhanced $\mathrm{pDC}: \mathrm{mDC}$ ratio after allergen challenge. In peripheral blood, there was a significant decrease in $m D C s(p=0.038)$ and a trend to a decrease in $p D C s(p=0.068) 24 \mathrm{~h}$ after allergen challenge. Analysis of dendritic cell surface molecules showed that after allergen challenge, BALF dendritic cells have a less mature phenotype compared with BALF dendritic cells from control segments.

Conclusion: Using a comprehensive strategy to analyse dendritic cell subsets in human BALF, we have shown for the first time that both myeloid and plasmacytoid dendritic cells accumulate in the airway lumen after allergen challenge in patients with asthma.
\end{abstract}

D endritic cells form a highly sensitive sentinel network in the lung. By continuously reporting antigenic information from the airways to pulmonary lymph nodes, they are capable of upregulating or downregulating specific immune responses in the lung. ${ }^{12}$ Animal models suggest that dendritic cells have a crucial role in asthma. ${ }^{3}$ Allergen challenge results in a recruitment of dendritic cells into the airways, which is essential for the establishment of allergic airway inflammation. ${ }^{45}$ Instillation of allergen-loaded dendritic cells into the airways alone can induce allergic airway inflammation in healthy animals. ${ }^{6}$ Selective elimination of dendritic cells during allergic airway inflammation abolishes the characteristic features of asthma, including eosinophilic inflammation, goblet cell hyperplasia and bronchial hyperresponsiveness. ${ }^{7}$ These data indicate that dendritic cells are vital for both the initiation and the maintenance of allergic airway inflammation in asthma. ${ }^{8}$

Human dendritic cells are identified by the abundant expression of major histocompatibility complex class II (HLADR) and the absence of lymphocyte, natural killer cell, monocyte and granulocyte lineage markers. ${ }^{2} \mathrm{CDIlc}^{+}$myeloid dendritic cells (mDCs) and $\mathrm{CDI}_{2} 3^{+}$plasmacytoid dendritic cells (pDCs) represent two main dendritic cell subtypes. There is ongoing research to further characterise these two dendritic cell subtypes in human lung parenchyma9 ${ }^{9-11}$ and in human bronchoalveolar lavage fluid (BALF). ${ }^{12}{ }^{13}$ Patients with asthma display increased numbers of intraepithelial dendritic cells in the airways compared with healthy individuals. ${ }^{14}{ }^{15}$ Allergen challenge causes an accumulation of $\mathrm{CDIl}^{+}$mDCs within the bronchial mucosa, ${ }^{16}$ and a parallel decline of these cells in circulating blood. ${ }^{17}$ In contrast, $\mathrm{CD} 123^{+}$pDC were postulated to be absent from the bronchial mucosa, both before and after allergen challenge, ${ }^{16}$ and have not yet been studied in peripheral blood after allergen challenge. ${ }^{17}$ However, local increases in pDCs have been reported in patients with atopic rhinitis and dermatitis after allergen challenge, ${ }^{18}{ }^{19}$ as well as elevated pDC counts in the peripheral blood of patients with allergic asthma. ${ }^{20}$ The relative contribution of mDCs and pDCs to the pathology of human asthma is, therefore, still unresolved. In addition, no information is available on the accumulation and the characteristics of pDCs and mDCs in BALF fluid after allergen challenge in human asthma. This study investigated dendritic cell subsets in human BALF after segmental allergen challenge using a comprehensive flow cytometric method.

\section{METHODS}

\section{Participants}

Seven patients with mild allergic asthma (median 23 years, range 19-25 years), most of them being medical students at the University of Rostock, volunteered for the study (table 1). Patients were recruited for the study on the basis of previously described criteria: (1) airway hyperresponsiveness; (2) positive allergen skin prick tests; (3) elevated total or specific IgE concentrations; and (4) a dual reaction after allergen

Abbreviations: BALF, bronchoalveolar lavage fluid; BDCA, blood dendritic cell antigen; $\mathrm{mDC}$, myeloid dendritic cell; $\mathrm{PDC}$, plasmacytoid dendritic cell 
Table 1 Patient characteristics

\begin{tabular}{|c|c|c|c|c|c|c|c|}
\hline No Sex & Age & $\begin{array}{l}\mathrm{FEV}_{1} \\
\text { (\% predicted) }\end{array}$ & Drugs & $\begin{array}{l}\text { Total lgE } \\
(\mathbf{k U} / \mathrm{l})\end{array}$ & $\begin{array}{l}\text { Specific lgE } \\
\text { (kU/I) }\end{array}$ & Allergen & Dose (AU) \\
\hline $1^{*} M$ & 23 & 77 & BA & 548 & 26.1 & Birch & 76 \\
\hline $2 \mathrm{~F}$ & 23 & 92 & BA & 564 & 77.1 & $\mathrm{DP}$ & 250 \\
\hline $3 \mathrm{~F}$ & 25 & 94 & $B A, I C$ & 96 & 4.0 & Birch & 30 \\
\hline $4 \mathrm{~F}$ & 25 & 105 & CR, BA & 64 & 16.9 & $\mathrm{DP}$ & 18 \\
\hline $\mathrm{F}$ & 23 & 105 & $\mathrm{BA}$ & 545 & 12.6 & Rye & 76 \\
\hline $6 \mathrm{~F}$ & 24 & 102 & BA & 155 & 5.2 & Rye & 4 \\
\hline $7 M$ & 19 & 114 & BA & 141 & 18.7 & Rye & 600 \\
\hline
\end{tabular}

$B A$, inhaled $\beta 2$ agonist; $C R$, cromoglycate; DP, dermatophagoides pteronyssinus; $F$, female; $F E V_{1}$, forced expiratory volume in the first second; IC, inhaled corticosteroid; lgE, immunoglobulin $\mathrm{E} ; \mathrm{M}$, male.

Table 1 displays the sex (male/female) and age (in years) of the patients, the prebronchodilator forced expiratory volume in the first second (FEV ${ }_{1}$ in $\%$ predicted), the drugs taken before the study, serum levels of total (normal range $<100 \mathrm{kU} / \mathrm{l}$ ) and allergen-specific (normal range $<0.7 \mathrm{kU} / \mathrm{l}$ ) immunoglobulin $\mathrm{E}$ (lgE) in kilo units (kU/l), and the allergen and the dose (in allergen units, AU) used for segmental allergen challenge. *Dendritic cell counts only from saline and allergen-challenged segments after $24 \mathrm{~h}$.

inhalation. ${ }^{21}$ The individual provocation dose was calculated as described. ${ }^{22}$ Inhaled and segmental allergen challenges were separated by at least 4 weeks. Corticosteroids were withdrawn at least 7 days before challenge. Patients gave their written informed consent. The study was approved by the local ethics committee.

\section{Segmental allergen challenge}

Segmental allergen challenge was performed as described previously..$^{21}$ Briefly, $2.5 \mathrm{ml}$ of saline were instilled into the left S8 (control 1, C1) and S5 (control 2, C2) segments, and allergen (diluted in $2.5 \mathrm{ml}$ of saline) was instilled into the right $\mathrm{S} 8$ (allergen 1, A1) and S5 (allergen 2, A2) segments. The left and right S8 ( $\mathrm{Cl}$ and $\mathrm{Al}$ ) segments were lavaged using $100 \mathrm{ml}$ of pre-warmed saline after $10 \mathrm{~min}$, and the left and right S5 segments (C2 and A2) after $24 \mathrm{~h}$. Median BALF recoveries were as follows: $\mathrm{Cl} 57 \mathrm{ml}$ (range 40-68 ml), Al $47 \mathrm{ml}(40-59 \mathrm{ml}$ ), C2 $62 \mathrm{ml}(50-75 \mathrm{ml})$ and A2 $60 \mathrm{ml}(22-64 \mathrm{ml})$. Before each bronchoscopy, venous blood samples were obtained.

\section{Analysis of cell counts and leucocyte subsets in BALF}

BALF samples were filtered through a two-layer sterile gauze into sterile plastic vials, centrifuged at $4^{\circ} \mathrm{C}$ and $500 \mathrm{~g}$ for $10 \mathrm{~min}$.
Cells were resuspended in phosphate-buffered saline. A fraction of the suspension was used for cell counts (using a Neubauer chamber; Brand, Wertheim, Germany) and for cytospins. Cytospins were stained with May/Grünwald/Giemsa solution (Merck, Darmstadt, Germany) and differential cell counts determined using standard morphological criteria. Results were expressed as the total number of cells per $\mathrm{ml}$ of recovered fluid.

\section{Flow cytometry}

Freshly collected EDTA blood and isolated BALF cells were incubated with the respective antibodies (table 2) for $20 \mathrm{~min}$. Afterwards, FACS lysing solution (BD Biosciences, Heidelberg, Germany) was added for another $10 \mathrm{~min}$. Cells were centrifuged for $5 \mathrm{~min}(400 \mathrm{~g})$ and washed with phosphate-buffered saline containing $2 \%$ fetal calf serum and $0.1 \% \mathrm{NaN}_{3}$. Finally, cells were resuspended in phosphate-buffered saline and analysed on a FACS Calibur using Cell Quest Pro Software (BD Biosciences). To identify dendritic cell subsets in BALF, we used an approach described previously to detect mDCs and pDCs in peripheral blood. ${ }^{20} \mathrm{CD} 3, \mathrm{CD} 14, \mathrm{CD} 16, \mathrm{CD} 19, \mathrm{CD} 20$ and CD56 negative/dim cells (lin $\left.{ }^{\text {neg/dim }}\right)$ were gated using a commercial lineage cocktail with antibodies against all of these antigens (fig 1A). Among these $\operatorname{lin}^{\text {neg/dim }}$ cells, distinct populations of CD123 ${ }^{+} \mathrm{HLA}^{-} \mathrm{DR}^{+}$cells

Table 2 Antibodies used for four-colour flow cytometry

\begin{tabular}{lllll}
\hline & Antigen & Label & Clone & Company \\
\hline Lineage cocktail & CD3 & FITC & SK7 & BD Biosciences \\
& CD14 & FITC & M $\phi$ P9 & BD Biosciences \\
& CD16 & FITC & 3 G & BD Biosciences \\
& CD19 & FITC & SJ25C1 & BD Biosciences \\
& CD20 & FITC & L27 & BD Biosciences \\
& CD56 & FITC & NCAM16.2 & BD Biosciences \\
& & & \\
Other antibodies & PE & S-HCL-3 & BD Biosciences \\
& CD1 1c & APC & S-HCL-3 & BD Biosciences \\
& CD123 & PE & 9F5 & BD Biosciences \\
& HLA-DR & PerCP & L243 & BD Biosciences \\
& CD40 & APC & HB14 & Caltag/lnvitrogen \\
& CD83 & APC & HB15e & Caltag/lnvitrogen \\
& CD86 & APC & BU63 & Immunotools \\
& CD80 & APC & MEM-233 & Dako \\
& CD1a & PE & NA1/34 & Miltenyi Biotec \\
& BDCA-1 & APC & AD5-8E7 & Miltenyi Biotec \\
& BDCA-2 & APC & AC144 & Miltenyi Biotec \\
& BDCA-3 & APC & AD5-14H12 & Miltenyi Biotec \\
& BDCA-4 & APC & AD5-17F6 &
\end{tabular}

APC, allophycocyanin; BDCA, blood dendritic cell antigen; FITC, fluorescein isothiocyanate; PE, phycoerythrin; PerCP, peridinin chlorophyll protein.

Caltag/Invitrogen, Karlsruhe, Germany; Dako, Glastrup, Denmark; Miltenyi Biotec, Bergisch Gladbach, Germany; Immunotods, Friesoythe, Germany. 

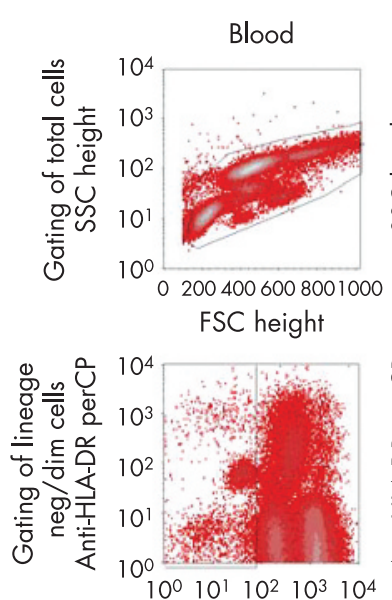

Lin I FITC

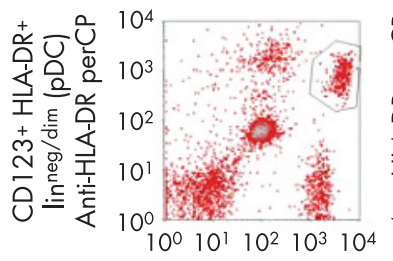

CD123 PE

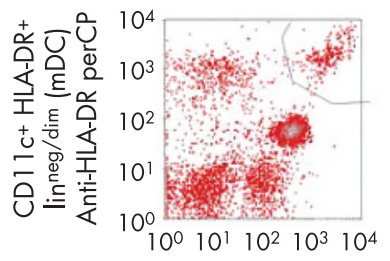

CDI lc PE

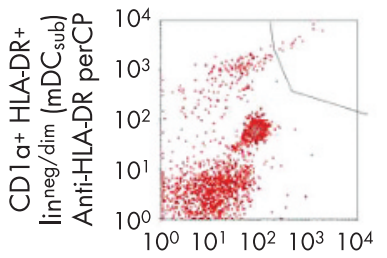

CD la PE
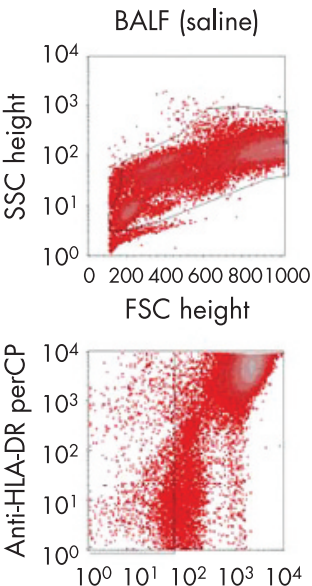

Lin 1 FITC

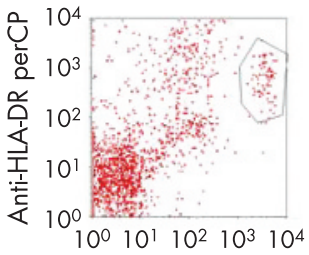

CD123 PE

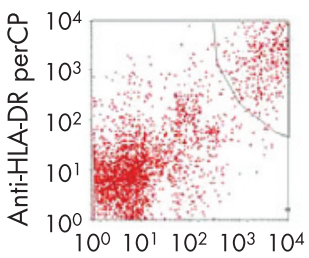

$\mathrm{CD} 1 \mathrm{1c} \mathrm{PE}$

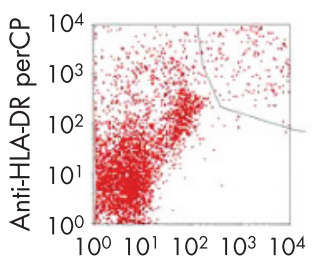

CDIa PE

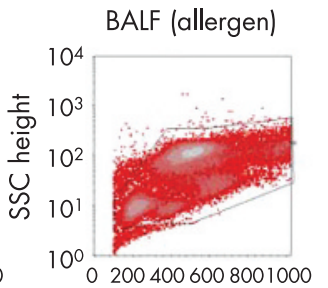

FSC height

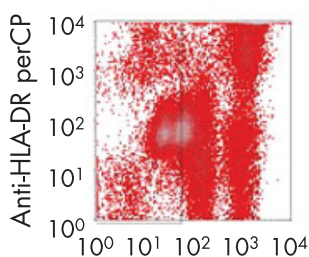

Lin 1 FITC

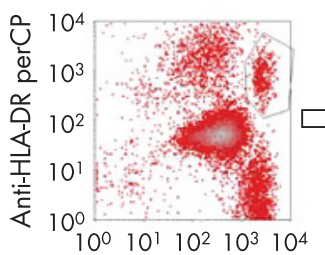

CD $123 \mathrm{PE}$

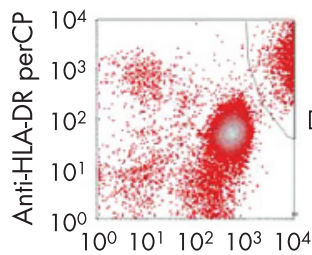

$\mathrm{CD} 1 \mathrm{lc} \mathrm{PE}$

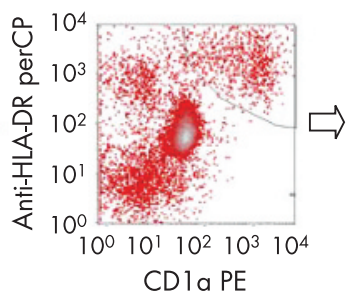

B

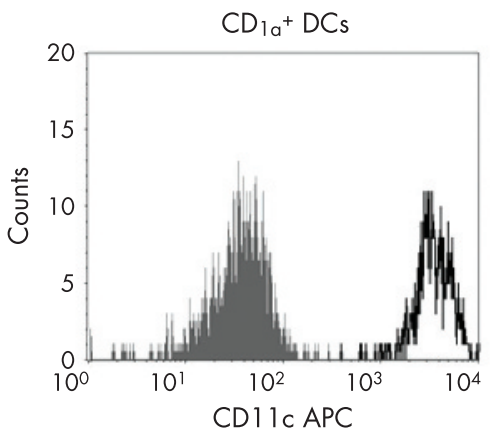

Blood
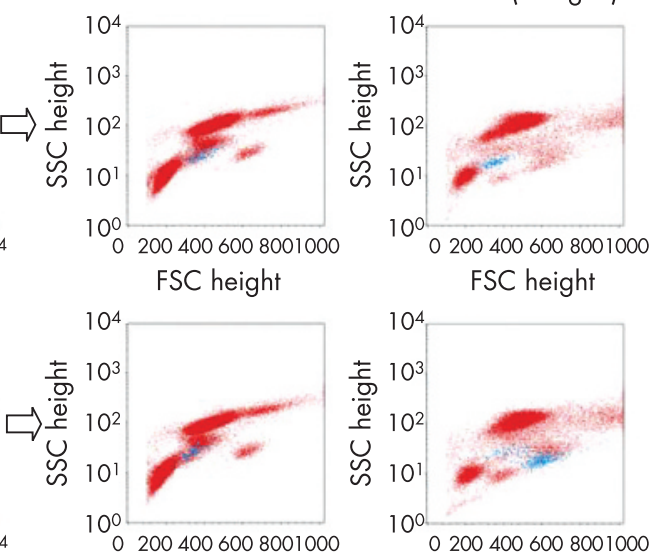

FSC height

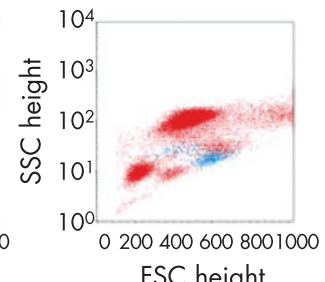

FSC height
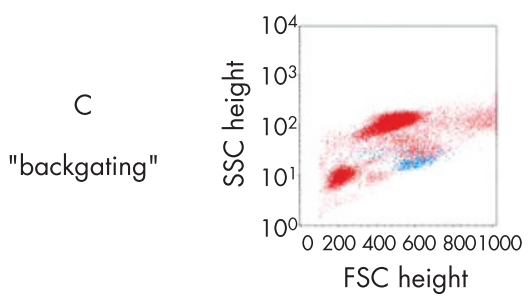

Figure 1 Identification of dendritic cell subsets in bronchoalveolar lavage fluid (BALF). (A) Total cells were identified in forward scatter/side scatter (FSC/ SSC) plots (first row). Lineage negative/dim (lin ${ }^{\text {neg/dim}) ~ c e l l s ~ w e r e ~ f u r t h e r ~ g a t e d ~(s e c o n d ~ r o w) ~ t o ~ i d e n t i f y ~ d e n d r i t i c ~ c e l l s . ~ A m o n g ~ l i n ~}{ }^{\text {neg/dim }}$ cells, plasmacytoid dendritic cells were identified by CDI 23 and HLA-DR expression (third row), myeloid dendritic cells by CD1 1 c and HLA-DR coexpression (fourth row) and $\mathrm{CD} \mathrm{la}{ }^{+}$dendritic cells by coexpression of CDla and HLA-DR (fifth row). (B) BALF-derived CD la dendritic cells were gated and analysed for CDI lc expression (black) compared with an isotype control antibody (grey). (C) Backgating of dendritic cell subsets showed distinct cell populations (blue) in the FSC/SSC plot.

(pDC) and CDllc $\mathrm{c}^{+} \mathrm{HLA}-\mathrm{DR}^{+}$cells (mDC) were identified, both in peripheral blood and in BALF (fig 1A). A population of CDla ${ }^{+}$HLA-DR ${ }^{+} l n^{\text {neg/dim }}$ cells identified in BALF could hardly be detected in peripheral blood (fig $\mathrm{IA}$ ). These $\mathrm{CDla}^{+}$dendritic cells coexpressed CDllc in all BALF samples, suggesting that these dendritic cells are a subpopulation of mDCs (fig 1B). Backgating showed that pDCs, mDCs and $\mathrm{CDla}^{+}$dendritic cells from BALF form distinct populations in the forward scatter/side scatter plot, without an overlap with lymphocyte, granulocyte and alveolar macrophage regions (fig lC).

\section{Statistical analysis}

Data were analysed using SPSS v 11.0. Most parameters were non-normally distributed. Therefore, correlation analysis was performed using Spearman's correlation coefficient, and the comparison of BALF parameters between allergen-challenged and saline-challenged control segments, and the comparison of blood parameters before and after allergen challenge was performed using Wilcoxon's signed rank test. The comparison of dendritic cells in peripheral blood and BALF was performed using the Mann-Whitney $U$ test. Probability values of $\mathrm{p}<0.05$ were regarded as significant.

\section{RESULTS}

Dendritic cell subsets in BALF and peripheral blood after segmental allergen challenge

In the BALF collected $24 \mathrm{~h}$ after saline challenge, low amounts of pDCs (median $0.06 \%$ or $0.06 \times 10^{3}$ cells $/ \mathrm{ml}$ BALF; range 
Total BALF cells (\%)
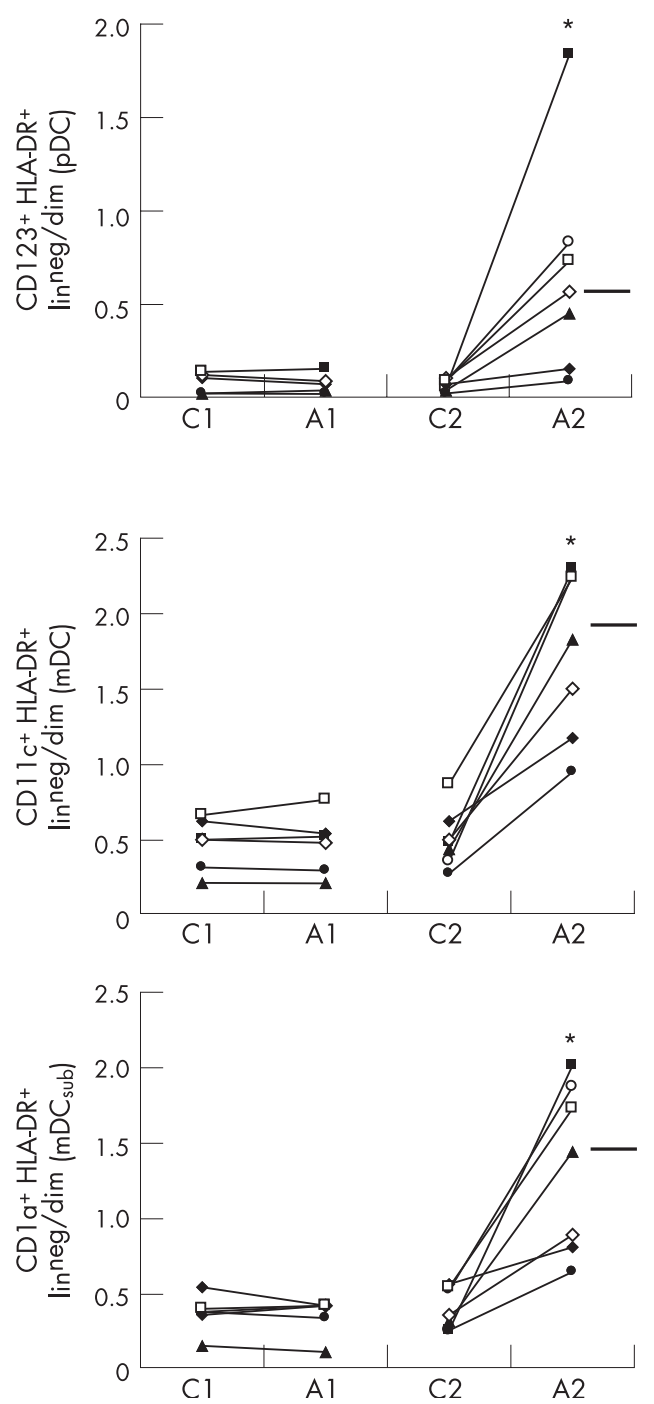

Cells $\left(10^{3} / \mathrm{ml} \mathrm{BALF}\right)$
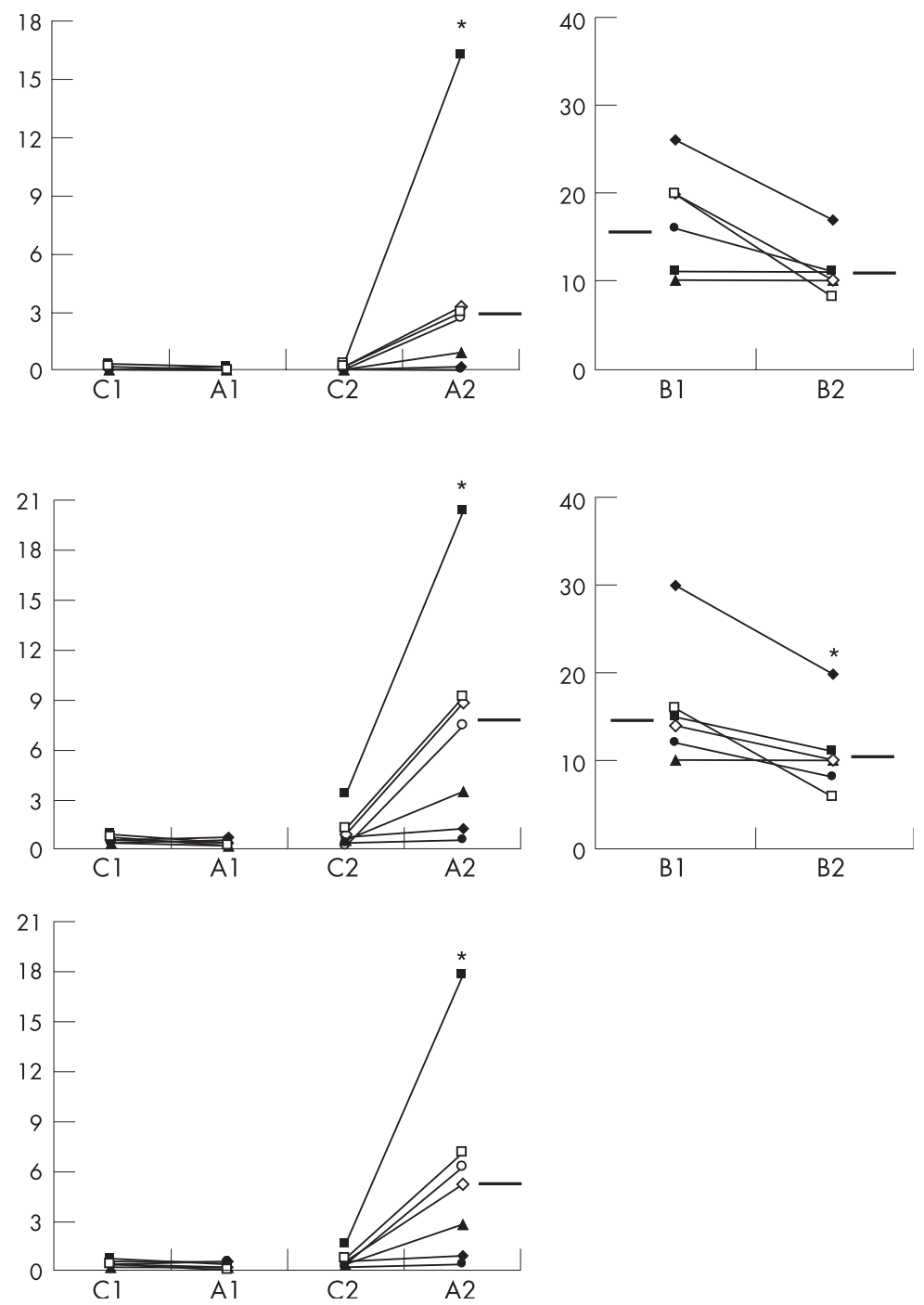

Figure 2 Dendritic cell subsets in bronchoalveolar lavage fluid (BALF) and peripheral blood after allergen challenge. Shown are percentages of dendritic cells in BALF and total dendritic cell counts in BALF and peripheral blood. A1, BALF 10 min after allergen challenge; A2, BALF 24 h after allergen challenge; $\mathrm{B1}$, peripheral blood before SAP; B2, peripheral blood $24 \mathrm{~h}$ after SAP; C1, BALF 10 min after saline challenge; C2, BALF $24 \mathrm{~h}$ after saline challenge. *Significant differences between allergen challenged and corresponding control segments, and between peripheral blood before and $24 \mathrm{~h}$ after allergenchallenge. Median values are displayed as bars for A2, B1 and B2. mDC, myeloid dendritic cells; pDC, plasmacytoid dendritic cells.

$0.01-0.08 \%$ or $0.01-0.34 \times 10^{3}$ cells $/ \mathrm{ml}$ BALF), mDCs (median $0.47 \%$ or $0.63 \times 10^{3}$ cells $/ \mathrm{ml}$ BALF; range $0.27-0.87 \%$ or $0.25-$ $3.2 \times 10^{3}$ cells $/ \mathrm{ml}$ BALF) and $\mathrm{CDla}^{+}$mDCs (median $0.34 \%$ or $0.56 \times 10^{3} \mathrm{cells} / \mathrm{ml}$ BALF; range $0.24-0.56 \%$ or $0.25-$ $1.63 \times 10^{3}$ cells/ml BALF) were detected. There were no significant differences in dendritic cell counts in BALF $10 \mathrm{~min}$ after saline challenge (fig 2). In all patients, the percentages as well as the total numbers of pDCs (median $0.56 \%$ or $2.71 \times 10^{3}$ cells $/ \mathrm{ml}$ BALF; range $0.09-1.83 \%$ or $0.06-$ $16.29 \times 10^{3}$ cells $/ \mathrm{ml}$ BALF; $p=0.018$ compared with the corresponding control), mDCs (median $1.82 \%$ or $7.45 \times 10^{3}$ cells $/ \mathrm{ml}$ BALF; range $0.95-2.29 \%$ or $0.60-20.38 \times 10^{3}$ cells/ml BALF; $\mathrm{p}=0.018$ ) and $\mathrm{CDla}{ }^{+}$mDCs (median $1.44 \%$ or $5.22 \times 10^{3}$ cells/ ml BALF; range $0.63-2.00 \%$ or $0.40-17.80 \times 10^{3}$ cells $/ \mathrm{ml} \mathrm{BALF;}$ $\mathrm{p}=0.018$ ) increased significantly in BALF $24 \mathrm{~h}$, but not $10 \mathrm{~min}$, after allergen challenge (fig 2). The percentage increase in pDCs was higher than the percentage increase in mDCs $24 \mathrm{~h}$ after allergen challenge in all patients. This was reflected by a significantly enhanced pDC:mDC ratio in allergen-challenged segments (median 0.36, range 0.09-0.80) as compared with control segments (median 0.11, range 0.04-0.23) after $24 \mathrm{~h}$ $(\mathrm{p}=0.018)$. In peripheral blood, distinct populations of pDCs and mDCs were detected before (median of pDCs $0.31 \%$, range $0.18-0.36 \%$; median of mDCs $0.26 \%$, range $0.17-0.36 \%$ ) and $24 \mathrm{~h}$ after allergen challenge (median of pDCs $0.14 \%$, range $0.09-0.25 \%$; median of mDCs $0.16 \%$, range $0.06-0.27 \%$ ). Total numbers of pDCs decreased in four of six patients and mDCs in five of six patients in peripheral blood $24 \mathrm{~h}$ after challenge (fig 2). This decrease in dendritic cell counts in peripheral blood was statistically significant in the case of mDCs $(p=0.038)$, but not in the case of pDCs $(\mathrm{p}=0.068)$.

\section{Association of dendritic cells with the inflammatory response and allergen dose}

Compared with the control segments, there were significantly increased neutrophil $(p=0.043)$ and eosinophil counts 
CD123+HLA-DR+ ${ }^{+}$in $^{\text {neg }} / \operatorname{dim}(p D C)$
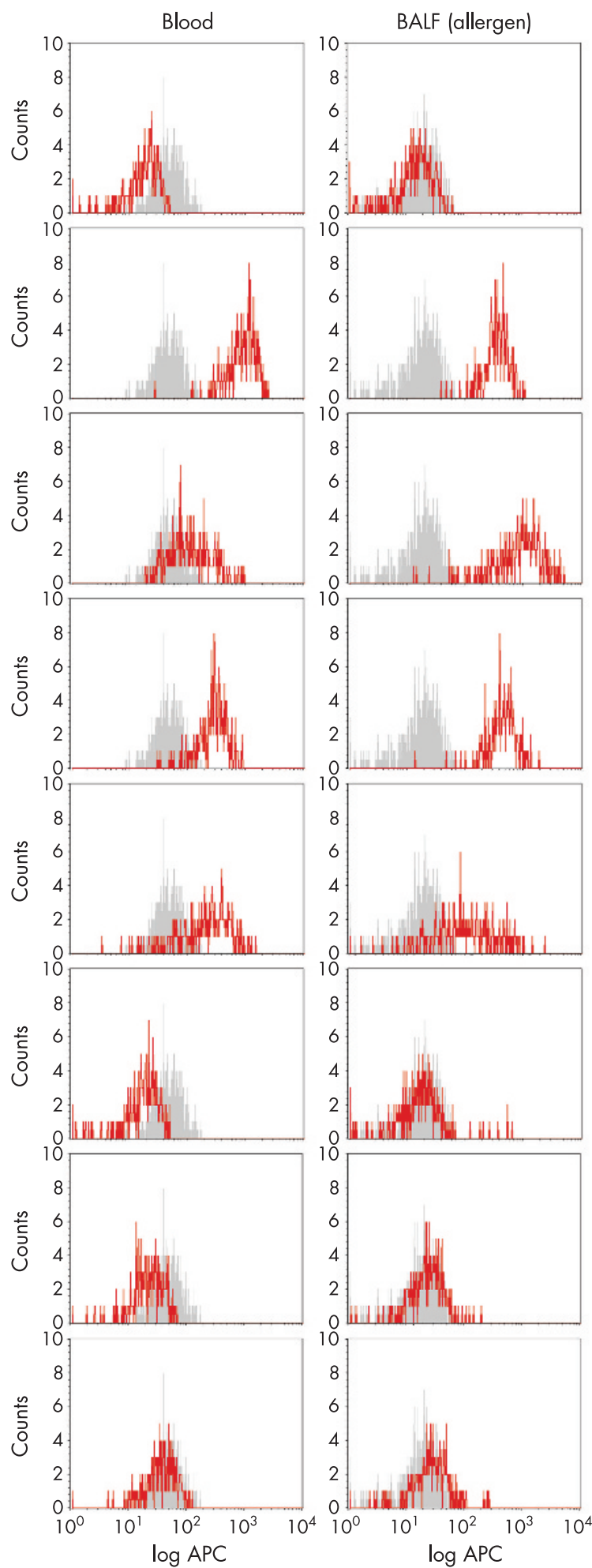

CD 123+HLA-DR ${ }^{+}$lin ${ }^{\text {neg }} / \operatorname{dim}(m D C)$
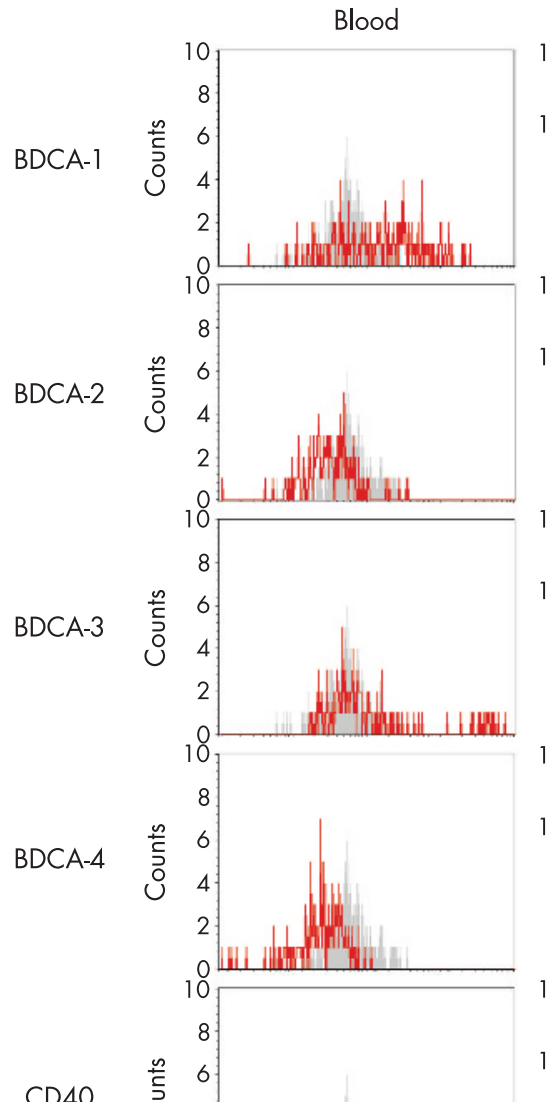

CD40
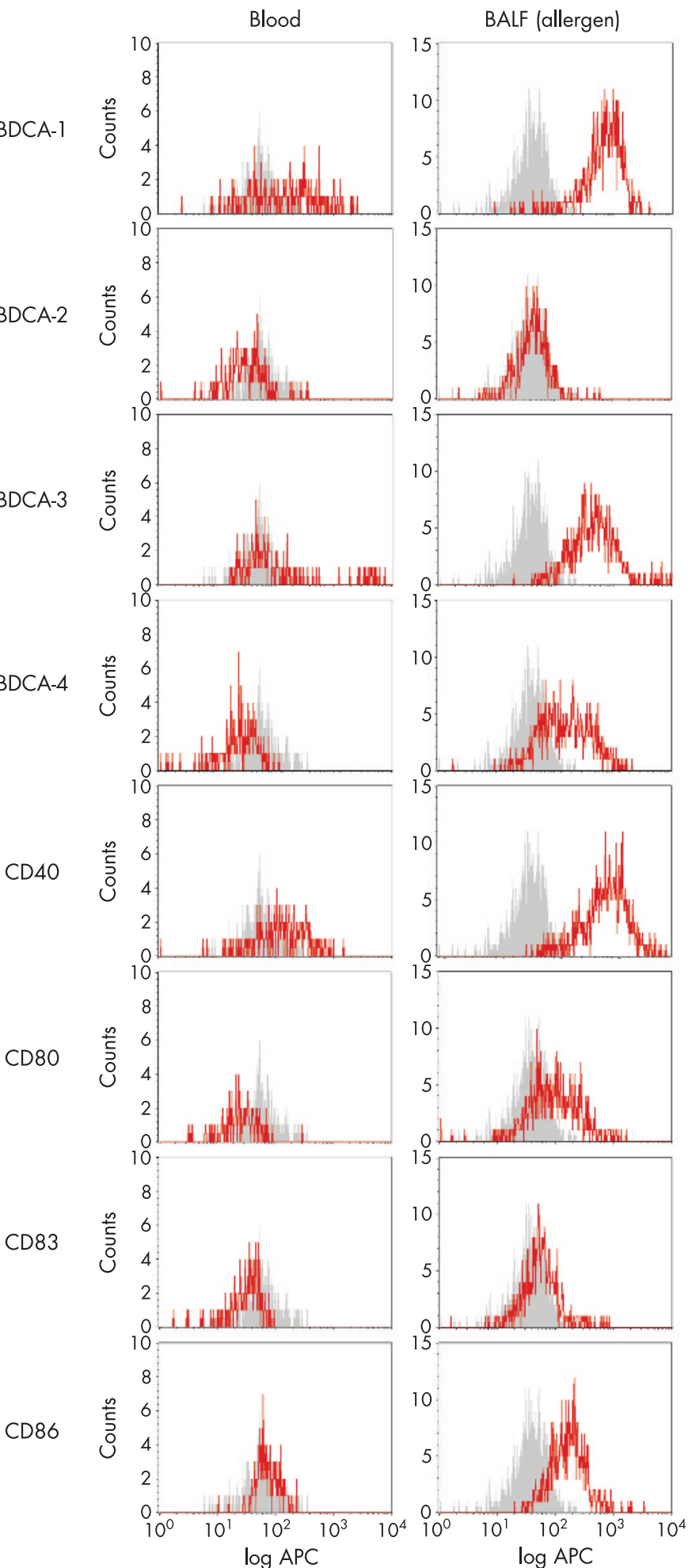

Figure 3 Surface molecules on dendritic cells in bronchoalveolar lavage fluid (BALF) and peripheral blood. Plasmacytoid dendritic cells (CD123+HLA$D R^{+} l n^{\text {neg/dim }}$ ) and myeloid dendritic cells (CD $11 c^{+} H L A-D R^{+} l i^{\text {neg/dim) }}$ were gated as described in fig 1 . Histograms display the expression of surface molecules (red) compared with corresponding isotype controls (grey). APC, allophycocyanin; BDCA, blood dendritic cell antigen.

$(\mathrm{p}=0.028)$ in BALF $24 \mathrm{~h}$, but not $10 \mathrm{~min}$, after challenge (see supplimentary table A online at http://www.thorax.bmjjournals.com/supplemental). The amount of infiltrating dendritic cells was correlated with the severity of the local inflammatory response, as reflected by a significant correlation between the total numbers of mDCs, $\mathrm{CDla}{ }^{+} \mathrm{mDCs}$ and pDCs with eosinophil counts ( $r>0.9$ and $p<0.001$ for all dendritic cell subsets) and lymphocyte counts $(\mathrm{r}=0.82-0.96, \mathrm{p}<0.05$ for all dendritic cell 
Table 3 Expression of surface molecules on dendritic cell subsets

\begin{tabular}{|c|c|c|c|c|c|}
\hline & B1 (\%) & B2 (\%) & $\mathrm{Cl}(\%)$ & C2 (\%) & A2 (\%) \\
\hline \multicolumn{6}{|l|}{$m D C$} \\
\hline BDCA-1 & $62.8(42.8$ to 80.8$)$ & 63.5 (38.4 to 82.6$)$ & 81.3 (65.0 to 94.7 ) & 85.9 (73.3 to 96.8$)$ & 92.6 (84.3 to 97.5$)$ \\
\hline BDCA-2 & $0.0(0.0$ to 6.8$)$ & $0.2(0.0$ to 10.1$)$ & $0.0(0.0$ to 0.4$)$ & $0.0(0.0$ to 0.4$)$ & $0.8(0.0$ to 2.3$)$ \\
\hline BDCA-3 & $19.6(15.6$ to 32.6$)$ & 23.8 (11.4 to 48.8 ) & 73.1 (57.6 to 94.2$)$ & 76.1 (61.2 to 87.7 ) & 87.5 (69.4 to 96.4 ) \\
\hline BDCA-4 & $0.0(0.0$ to 2.9$)$ & $0.0(0.0$ to 4.6$)$ & $20.0(0.2$ to 52.2$)$ & 23.3 (15.0 to 43.2 ) & 45.1 (10.8 to 81.5$)$ \\
\hline CD40 & 43.4 (13.4 to 54.2$)$ & 33.0 (11.2 to 75.8$)$ & $98.0(93.1$ to 100.0$)$ & 95.1 (92.9 to 99.3 ) & $96.6(90.1$ to 99.1$)$ \\
\hline CD80 & $0.0(0.0$ to 0.9$)$ & $0.0(0.0$ to 0.5$)$ & $70.8(50.6$ to 80.9$)$ & 58.6 (39.8 to 75.8$)$ & 43.3 (16.9 to 62.0$)$ \\
\hline CD83 & 0.0 & 0.0 & 26.5 (19.9 to 33.3$)$ & 27.6 (12.7 to 38.1$)$ & $11.1(7.3$ to 25.1$)$ \\
\hline CD86 & $1.0(0.0$ to 7.2$)$ & $1.5(0.0$ to 8.2$)$ & 84.3 (65.8 to 90.0 ) & 87.0 (67.6 to 93.0$)$ & 78.9 (39.4 to 86.8 ) \\
\hline CDla & bd & bd & 71.8 (60.0 to 100.0 ) & $69.6(51.1$ to 91.8$)$ & 72.9 (59.3 to 87.3$)$ \\
\hline \multicolumn{6}{|l|}{$\mathrm{pDC}$} \\
\hline BDCA-1 & 0.0 & 0.0 & NA & NA & $0.0(0.0$ to 3.4$)$ \\
\hline BDCA-2 & 99.2 (94.7 to 99.7 ) & $98.9(96.1$ to 100.0$)$ & NA & NA & 98.1 (91.1 to 100.0$)$ \\
\hline BDCA-3 & $53.2(17.3$ to 73.5$)$ & 52.1 (28.4 to 65.5$)$ & NA & NA & 97.1 (94.9 to 100.0$)$ \\
\hline BDCA-4 & 94.2 (92.3 to 99.7 ) & 96.5 (92.9 to 100.0$)$ & NA & NA & 96.4 (77. 4 to 99.5$)$ \\
\hline CD40 & $88.4(27.2$ to 92.6$)$ & $82.6(23.8$ to 89.9$)$ & NA & NA & 57.1 (36.8 to 77.7 ) \\
\hline CD80 & 0.0 & 0.0 & NA & NA & 9.5 (2.5 to 30.0$)$ \\
\hline CD83 & 0.0 & 0.0 & NA & NA & $0.0(0.0$ to 2.3$)$ \\
\hline CD86 & $0.0(0.0$ to 0.6$)$ & 0.0 (0.0 to 3.2$)$ & NA & NA & $9.0(0.6$ to 12.5$)$ \\
\hline
\end{tabular}

A2, bronchoalveolar lavage fluid (BALF) $24 \mathrm{~h}$ after allergen challenge; B1, peripheral blood before allergen challenge; B2, peripheral blood $24 \mathrm{~h}$ after allergen challenge; bd, below detection limit; BDCA, blood dendritic cell antigen; C1, BALF 10 min after saline challenge; C2, BALF 24 h after saline challenge; mDC, myeloid dendritic cells; NA, not analysable; pDC, plasmacytoid dendritic cells.

Values in parentheses denote ranges (minimum to maximum).

subsets) in BALF $24 \mathrm{~h}$ after challenge. There was also a correlation between the total numbers of mDCs, $\mathrm{CDla}^{+} \mathrm{mDCs}$ and pDCs and the allergen dose used for challenge $(r>0.86$ and $\mathrm{p}<0.01$ for all dendritic cell subsets).

\section{Surface molecules on dendritic cells in BALF and peripheral blood}

Both in peripheral blood and in BALF, the expression of blood dendritic cell antigen (BDCA)-2 was restricted to pDCs, whereas BDCA-1 expression was restricted to a subset of mDCs (fig 3, table 3). In contrast with peripheral blood, BDCA-3 was expressed not only on a subset of mDCs but also on pDCs and most BDCA- $\mathrm{I}^{+}$mDCs in BALF. BDCA-4, which was restricted to pDCs in peripheral blood, was also expressed on a subset of BALF mDCs (fig 3, table 3). This subset of BDCA- $4^{+}$BALF mDCs increased twofold $24 \mathrm{~h}$ after allergen challenge compared with the control segments (table 3 ). Of note, BDCA-3 and BDCA-4 were strongly expressed by other BALF cells that were lin $^{\text {bright }}$ and HLA-DR ${ }^{+}$. As eosinophils, neutrophils and macrophages were excluded by gating, other lineage-positive cells must account for this expression. In addition, some expression of BDCA-3 and BDCA-4 was found on alveolar macrophages and granulocytes (see supplementary fig A online at http://www.thorax.bmjjournals.com/supplement). Compared with peripheral blood mDCs, the expression of CD40, CD80 and CD86 was significantly stronger on mDCs from BALF of control segments $(\mathrm{p}<0.05$ in all cases; fig 3, table 3). The dendritic cell maturation marker CD83 was absent on blood mDCs, but detectable on approximately $25 \%$ of BALF mDCs from the control segments. The mDCs in BALF $24 \mathrm{~h}$ after allergen challenge were characterised by a significantly lower expression of CD83 compared with the corresponding control segments ( $p=0.046$; fig 3 , table 3 ). Owing to the very low number of pDCs in BALF, it was not possible to reliably analyse surface markers on pDCs in the control segments. Only CD40, but not CD80, CD83 or CD86, was expressed on pDCs in peripheral blood. In contrast, a low expression of CD80 and CD86 was found on BALF pDCs $24 \mathrm{~h}$ after challenge. There was a non-significant trend to a decreased expression of CD40 on BALF pDCs compared with blood pDCs $24 \mathrm{~h}$ after challenge ( $\mathrm{p}=0.09$; fig 3 , table 3 ).

Table 3 displays the percentage of marker-positive mDCs and pDCs in blood $(\mathrm{B} 1, \mathrm{~B} 2)$ or $\operatorname{BALF}(\mathrm{Cl}, \mathrm{C} 2, \mathrm{~A} 2)$. The median values (range) of six patients with asthma are presented. The time point $10 \mathrm{~min}$ after allergen challenge $(\mathrm{Al})$ is not displayed, because cell counts in BALF were too low to measure surface molecules on dendritic cells. In BALF from salinechallenged control segments ( $\mathrm{Cl}$ and $\mathrm{C} 2)$, numbers of pDCs were too low to quantify the expression of surface molecules.

\section{DISCUSSION}

In this study, we have reported a comprehensive strategy for the identification, quantification and characterisation of plasmacytoid dendritic cells $\left(\mathrm{CD} 123^{+} \mathrm{HLA}-\mathrm{DR}^{+} \mathrm{lin}^{\text {neg/dim }}\right)$ and myeloid dendritic cells (CD1lc ${ }^{+}$HLA-DR ${ }^{+} l n^{\text {neg/dim }}$ ) in human BALF using four-colour flow cytometry. In addition, this is the first study in humans to show that allergen challenge is associated with a marked influx of both pDCs and mDCs into the airway lumen of patients with allergic asthma. Further, it provides a detailed analysis of the distribution of dendritic cell antigens on these infiltrating dendritic cells. Although our study included a comparably small number of patients, the uniformity of the data suggests that our results are representative for a larger population and that a larger number of patients would not have changed the findings considerably.

Dendritic cells in BALF were initially identified using immunocytochemistry, and were postulated to yield approximately $0.4 \%$ of all cells in the BALF of healthy patients. ${ }^{23}$ In subsequent studies, the same group identified dendritic cells by their low autofluorescent properties in flow cytometric analyses, and divided these low autofluorescent cells into subgroups of $\mathrm{CDla}^{+}$and $\mathrm{CDla}{ }^{-}$cells. ${ }^{24}{ }^{25}$ Using flow cytometry with a different gating strategy compared with our study, Donnenberg and Donnenberg recently described $\mathrm{CD}_{2} 23^{+}$ plasmacytoid dendritic cells $(0.02 \%)$ and $\mathrm{CDIlc}^{+}$myeloid dendritic cells $(0.06 \%)$ in BALF from healthy volunteers. ${ }^{12}$ Our study is the first to use all three markers (CDla, CDllc and CD123) to characterise dendritic cells in BALF. With this approach, we identified $\mathrm{CDla}^{+}$dendritic cells as a subset of mDCs in BALF. This $\mathrm{CDla}^{+}$subset of mDCs represented the majority of BALF mDCs, but was nearly absent among peripheral blood mDCs, suggesting that $\mathrm{CDla}$ is upregulated during the passage of mDCs into the airways. $\mathrm{CDla}^{+}$dendritic cells were previously described as intraepithelial dendritic cells, 
with a yet undefined relationship with mDCs. ${ }^{2}$ Our data provide evidence that these cells represent a subgroup of mDCs in BALF.

Recently, the use of magnetic beads targeting blood dendritic cell antigens (BDCA 1-4) has been proposed as a straightforward strategy to isolate subsets of dendritic cells from lung homogenates ${ }^{10}{ }^{11}$ and BALF. ${ }^{13}$ In peripheral blood, BDCA-2 and BDCA- 4 are confined to pDCs, whereas BDCA-1 and BDCA-3 are confined to mDCs. ${ }^{26}$ In agreement with this distribution in peripheral blood, BDCA-1 was confined to mDCs and BDCA-2 to pDCs in BALF. However, there was a rather unspecific expression of BDCA-3 and BDCA-4 in BALF. BDCA-3 was also expressed on pDCs, BDCA $-1^{+}$mDCs and a variety of other BALF cells including a population of lin ${ }^{\text {bright }} \mathrm{HLA}-\mathrm{DR}^{+}$cells within the lymphocyte/dendritic cell gate. BDCA-4 was expressed on mDCs and a lin ${ }^{\text {bright }}$ HLA-DR ${ }^{+}$cell population in BALF. These data suggest that BDCA-3 and BDCA-4 are not specific for mDCs or pDCs in the BALF of patients with allergic asthma. In addition, the previously reported BDCA $-3^{+} \mathrm{HLA}-\mathrm{DR}^{+}$dendritic cell subset in lung homogenates termed "mDC2" ${ }^{\prime 10}{ }^{11}$ might also contain pDCs. This hypothesis is supported by the findings that a subpopulation of $\mathrm{mDC} 2$ is $\mathrm{CDIlc}^{-},{ }^{10}$ and that the $\mathrm{T}$ cell proliferation induced by $\mathrm{mDC} 2$ ranges between that induced by mDCl and pDC. ${ }^{11}$ Therefore, further analysis of the cellular distribution of BDCA molecules in human BALF or lung homogenates will be required before anti-BDCA-3 and antiBDCA- 4 beads can be recommended as a suitable tool to isolate subsets of pulmonary dendritic cells.

There is accumulating evidence from animal models that mDCs have a crucial role in the development and maintenance of allergic asthma. ${ }^{36}$ In contrast, pDCs have been reported to inhibit allergic airway inflammation and Th2-type cytokine production in a mouse model of asthma. ${ }^{27}$ It has therefore been hypothesised that mDCs and pDCs might be in a yin-yang balance in allergic asthma, with a proallergic role of mDCs and antiallergic properties of pDCs. However, there is uncertainty whether this concept is applicable to human asthma. Plasmacytoid dendritic cells are increased in the peripheral blood of patients with allergic asthma and other atopic diseases, and are positively correlated with IgE levels and eosinophil counts. ${ }^{20} 28$ In patients with atopic rhinitis and dermatitis, there is a strong local increase in pDCs after allergen challenge. $^{18}{ }^{19}$ Human pDCs can stimulate allergen-dependent T cell proliferation and Th2-type cytokine production as efficiently as mDCs, but are also capable of Thl-type cytokine production after stimulation with CpG motifs. ${ }^{30}$ A recent report suggests that the decision as to whether pDCs will trigger either a Th1-type or a Th2-type immune response may be dependent on the local microenvironment and pre-stimulation with Thltype or Th2-type mediators. ${ }^{31}$ Therefore, the precise role of pDCs in human asthma is still unclear.

We show for the first time that allergen challenge is associated with a marked influx of both mDCs and pDCs into BALF in patients with asthma. Of note, the percentage increase of pDCs in BALF was higher than that of mDCs in BALF, as reflected by an enhanced pDC:mDC ratio after allergen challenge. In keeping with previous data, ${ }^{17}$ there was a decrease in mDCs in peripheral blood after allergen challenge. In addition, there was a trend to a decrease in peripheral blood pDCs in this condition. These data suggest that both mDCs and pDCs are recruited from peripheral blood to the human respiratory tract after allergen challenge. Migration of immature peripheral blood dendritic cells into the airways would also explain the observation that the percentage of mature $\mathrm{CD}^{+} 3^{+}$ mDCs was significantly reduced in BALF after allergen challenge. However, the decrease in mature $\mathrm{CD} 83^{+}$mDCs in BALF might also be due to migration of mature endobronchial
mDCs to mediastinal lymph nodes after allergen challenge. Notably, the number of local effector cells (such as eosinophils and lymphocytes) was correlated with the number of infiltrating dendritic cells after allergen challenge. This finding suggests that the amount of dendritic cells recruited into the airways might be linked to or triggered by airway inflammation. Thus, according to the concept that dendritic cells have a role in maintaining an established airway inflammation in asthma, an inflammation-triggered recruitment of dendritic cells into the airways could represent a vicious cycle in allergic asthma. It remains to be elucidated, however, whether the recruited mDCs and pDCs have similar or opposing roles in this condition.

In conclusion, we described a strategy to comprehensively analyse dendritic cell subsets and dendritic cell surface molecules in human bronchoalveolar lavage fluid. Using this strategy, we showed a marked local increase of not only mDCs but also pDCs after allergen challenge in patients with asthma, which suggests that both dendritic cell subsets are involved in the pathogenesis of asthma.

\section{ACKNOWLEDGEMENTS}

We thank Petra Thamm for excellent technical assistance.

\section{Authors' affiliations}

Kai Bratke*, Marek Lommatzsch*, Peter Julius, Michael Kuepper, Werner Luttmann, J Christian Virchow, Department of Pneumology, University of Rostock, Rostock, Germany

Hans-Dieter Kleine, Department of Hematology and Oncology, University of Rostock, Rostock, Germany

*Both authors contributed equally.

Funding: Deutsche Forschungsgemeinschaft (DFG) (Grant LO 1145/2-1).

Competing interests: None.

Ethical approval: This study was approved by the local ethics committee of Rostock, Germany.

\section{REFERENCES}

1 Banchereau J, Steinman RM. Dendritic cells and the control of immunity. Nature 1998;392:245-52.

2 Vermaelen K, Pauwels R. Pulmonary dendritic cells. Am J Respir Crit Care Med 2005;172:530-51.

3 Lambrecht BN, Hammad H. Taking our breath away: dendritic cells in the pathogenesis of asthma. Nat Rev Immunol 2003;3:994-1003.

4 Lambrecht BN, Carro-Muino I, Vermaelen K, et al. Allergen-induced changes in bone-marrow progenitor and airway dendritic cells in sensitized rats. Am J Respir Cell Mol Biol 1999;20:1165-74.

5 Vermaelen KY, Cataldo D, Tournoy K, et al. Matrix metalloproteinase-9mediated dendritic cell recruitment into the airways is a critical step in a mouse model of asthma. J Immunol 2003;171:1016-22.

6 Lambrecht BN, De Veerman M, Coyle AJ, et al. Myeloid dendritic cells induce Th2 responses to inhaled antigen, leading to eosinophilic airway inflammation. $J$ Clin Invest 2000;106:551-9.

7 van Riji LS, Jung S, Kleinjan A, et al. In vivo depletion of lung CDI lc+ dendritic cells during allergen challenge abrogates the characteristic features of asthma. J Exp Med 2005;201:981-91.

8 van Rijt LS, Lambrecht BN. Dendritic cells in asthma: a function beyond sensitization. Clin Exp Allergy 2005;35:1125-34.

9 Cochand $\mathrm{L}$, Isler $\mathrm{P}$, Songeon $\mathrm{F}$, et al. Human lung dendritic cells have an immature phenotype with efficient mannose receptors. Am J Respir Cell Mol Biol 1999;21:547-54.

10 Demedts IK, Brusselle GG, Vermaelen KY, et al. Identification and characterization of human pulmonary dendritic cells. Am J Respir Cell Mol Biol 2005;32:177-84.

11 Demedts IK, Bracke KR, Maes T, et al. Different roles for human lung dendritic cell subsets in pulmonary immune defense mechanisms. Am J Respir Cell Mol Biol 2006;35:387-93.

12 Donnenberg VS, Donnenberg AD. Identification, rare-event detection and analysis of dendritic cell subsets in broncho-alveolar lavage fluid and peripheral blood by flow cytometry. Front Biosci 2003;8:s $1175-80$.

13 Tsoumakidou M, Tzanakis N, Papadaki HA, et al. Isolation of myeloid and plasmacyłoid dendritic cells from human bronchoalveolar lavage fluid. Immunol Cell Biol 2006;84:267-73. 
14 Bellini A, Vittori E, Marini M, et al. Intraepithelial dendritic cells and selective activation of Th2-like lymphocytes in patients with atopic asthma. Chest 1993;103:997-1005

15 Moller GM, Overbeek SE, Van Helden-Meeuwsen CG, et al. Increased numbers of dendritic cells in the bronchial mucosa of atopic asthmatic patients: downregulation by inhaled corticosteroids. Clin Exp Allergy 1996;26:517-24.

16 Jahnsen FL, Moloney ED, Hogan T, et al. Rapid dendritic cell recruitment to the bronchial mucosa of patients with atopic asthma in response to local allergen challenge. Thorax 2001;56:823-6.

17 Upham JW, Denburg JA, O'Byrne PM. Rapid response of circulating myeloid dendritic cells to inhaled allergen in asthmatic subjects. Clin Exp Allergy 2002;32:818-23.

18 Jahnsen FL, Lund-Johansen F, Dunne JF, et al. Experimentally induced recruitment of plasmacytoid (CD123high) dendritic cells in human nasal allergy. $J$ Immunol 2000; 165:4062-8.

19 Bangert C, Friedl J, Stary G, et al. Immunopathologic features of allergic contact dermatitis in humans: participation of plasmacytoid dendritic cells in the pathogenesis of the disease? J Invest Dermatol 2003;121:1409-18.

20 Matsuda $\mathrm{H}$, Suda T, Hashizume $\mathrm{H}$, et al. Alteration of balance between myeloid dendritic cells and plasmacytoid dendritic cells in peripheral blood of patients with asthma. Am J Respir Crit Care Med 2002;166:1050-4.

21 Lommatzsch $M$, Julius $P$, Kuepper $M$, et al. The course of allergen-induced leukocyte infiltration in human and experimental asthma. J Allergy Clin Immunol 2006;118:91-7.

22 Nassenstein C, Braun A, Erpenbeck VJ, et al. The neurotrophins nerve growth factor, brain-derived neurotrophic factor, neurotrophin-3, and neurotrophin-4 are survival and activation factors for eosinophils in patients with allergic bronchial asthma. J Exp Med 2003;198:455-67.
23 van Haarst JM de Wit $\mathrm{HJ}$, Drexhage HA et al. Distribution and immunophenotype of mononuclear phagocytes and dendritic cells in the human lung. Am J Respir Cell Mol Biol 1994;10:487-92.

24 van Haarst JM, Hoogsteden HC, de Wit HJ, et al. Dendritic cells and their precursors isolated from human bronchoalveolar lavage: immunocytologic and functional properties. Am J Respir Cell Mol Biol 1994;11:344-50.

25 van Haarst JM, Verhoeven GT, de Wit HJ, et al. CDla+ and CDIa- accessory cells from human bronchoalveolar lavage differ in allostimulatory potential and cytokine production. Am J Respir Cell Mol Biol 1996;15:752-9.

26 Dzionek A, Fuchs A, Schmidt P, et al. BDCA-2, BDCA-3, and BDCA-4: three markers for distinct subsets of dendritic cells in human peripheral blood. $\mathrm{J}$ Immunol 2000;165:6037-46.

27 de Heer HJ, Hammad H, Soullie T, et al. Essential role of lung plasmacytoid dendritic cells in preventing asthmatic reactions to harmless inhaled antigen. J Exp Med 2004;200:89-98.

28 Uchida Y, Kurasawa K, Nakajima H, et al. Increase of dendritic cells of type 2 (DC2) by altered response to IL-4 in atopic patients. J Allergy Clin Immunol 2001;108:1005-11.

29 Hashizume $\mathbf{H}$, Horibe T, Yagi $\mathrm{H}$, et al. Compartmental imbalance and aberrant immune function of blood CD123+ (plasmacytoid) and CD1 lc+ (myeloid) dendritic cells in atopic dermatitis. J Immunol 2005; 174:2396-403.

30 Farkas L, Kvale EO, Johansen FE, et al. Plasmacytoid dendritic cells activate allergen-specific TH2 memory cells: modulation by $\mathrm{CpG}$ oligodeoxynucleotides. J Allergy Clin Immunol 2004;114:436-43.

31 Schroeder JT, Bieneman AP, Xiao H, et al. TLR9- and FcepsilonRI-mediated responses oppose one another in plasmacytoid dendritic cells by downregulating receptor expression. $J$ Immunol 2005; 175:5724-31. 